\title{
Analiza czynników determinujących rozwój intelektualny dzieci i młodzieży z przepukliną oponowo-rdzeniową
}

\section{Analysis of factors determining mental development of children and youth with meningomyelocele}

\author{
Wojciech Kułak, Dorota Sienkiewicz, Bożena Okurowska-Zawada, Janusz Wojtkowski, \\ Grażyna Paszko-Patej
}

Klinika Rehabilitacji Dziecięcej z Klinika Rehabilitacji Dziecięcej z Ośrodkiem Wczesnej Pomocy Dzieciom Upośledzonym "Dać Szansę", ul. Waszyngtona 17, 15-274 Białystok, tel. Fax 857450601

DOI:10.20966/chn.2017.53.407

\section{STRESZCZENIE}

Wprowadzenie: Przepuklina oponowo-rdzeniowa jest wadą wrodzoną układu nerwowego w której oprócz niedowładów lub porażeń kończyn dolnych może występować nieprawidłowy rozwój intelektualny. Cel badań: Ocena czynników determinujących rozwój intelektualny dzieci i młodzieży z przepukliną oponowo-rdzeniową. Materiał i metody: Badaniem objęto 52 dzieci i mtodzieży z przepukliną oponowo-rdzeniową w wieku 4-17 lat 19,1 $\pm 3,8$ lat), 56\% dziewcząt i 44\% chłopców. Rozwój intelektualny analizowano na podstawie przeprowadzonych wcześniej badań w Poradni Psychologiczno-Pedagogicznej. Oceniano stan funkcjonalny pacjentów za pomocą skali Hoffer'a oraz poziom uszkodzenia rdzenia. Do analizy rozwoju intelektualnego brano pod uwagę: czynniki demograficzne, dane z wywiadu okołoporodowego, rozwój ruchowy, stan funkcjonalny i kliniczny oraz wykształcenie rodziców. Wyniki: Przepuklinę oponowo-rdzeniową okolicy lędźwiowo-krzyżowej stwierdzono w 56\%, piersiowo-lędźwiową (38\%) i krzyżową u 6\%. Ponad połowa badanych $(56 \%)$ poruszała się na wózku inwalidzkim. Nieprawidłowy rozwój intelektualny wykazano u $39 \%$. Stwierdzono dodatnie korelacje pomiędzy rozwojem intelektualnym pacjentów a wiekiem rozpoczęcia chodzenia i wykształceniem matki. Wykazano ujemne zależności pomiędzy rozwojem intelektualnym badanych a stanem funkcjonalnym, obecnością wodogłowia i drenażu komorowo-otrzewnowego. Wnioski: Rozwój intelektualny badanej grupy z przepukliną oponowo-rdzeniową był związany z wiekiem rozpoczęcia chodu, wykształceniem matki, stanem funkcjonalnym, obecnością wodogłowia i drenażu komorowo-otrzewnowego.

Słowa kluczowe: Przepuklina oponowo-rdzeniowa, stan funkcjonalny, rozwój intelektualny
ABSTRACT

Introduction: Meningomyelocele is a congenital malformation of the nervous system in which, in addition to paresis or paralysis of the lower limbs, mental retardation occurs. Aim of the study: Assessment of factors determining the mental development of children and adolescents with meningomyelocele. Material and methods: 52 children and adolescents, $56 \%$ girls and $44 \%$ boys with meningomyelocele aged $4-17$ years $(9.1 \pm 3.8$ years), were studied. The mental development was analysed on the basis of previous tests in the Psychological and Pedagogical Outpatient Clinic. The Hoffer's Scale of functional ambulation and the level of spinal cord damage were evaluated. For the mental development analysis the demographic factors, perinatal data, psychomotor development, functional and clinical status and parental education were included. Results: The lumbosacral meningomyelocele was found in $56 \%$, thoracic-lumbar in $38 \%$ and sacral in $6 \%$. More than half of the subjects (56\%) were wheelchair-bound. Abnormal mental development was found in $39 \%$. Positive correlations between the mental development of subjects and age of walking and mother's education were found. Negative correlations were found between the mental development of the subjects and functional status, hydrocephalus and shunt. Conclusions: The mental development of the study subjects with meningomyelocele was related to the age at which the gait started, mother's education, functional status, presence of hydrocephalus and shunt.

Key words: Meningomyelocele, functional status, mental development

\section{WPROWADZENIE}

Przepuklina oponowo-rdzeniowa jest wrodzonym zaburzeniem należącym do wad cewy nerwowej, w którym zmiany dotyczą rdzenia kręgowego i ośrodkowego układu nerwowego [1]

Częstość występowania wad cewy nerwowej w latach 2003-2004 wynosiła w Polsce 8,1/10 000 urodzeń i była istotnie wyższa, niż średnia dla wszystkich krajów EUROCAT (2,6 na 10000 żywych urodzeń) [2].
Następstwa przepukliny oponowo-rdzeniowej dotyczą zarówno sfery fizycznej, jak i umysłowej chorego oraz utrzymują się przez całe życie [2-5]. Rozwój ruchowy jest opóźniony w zakresie motoryki dużej i małej oraz koordynacji wzrokowo-ruchowej, wpływając negatywnie na zdobywanie wiadomości i doświadczeń z otoczenia oraz nauki w szkole. U dzieci z uszkodzeniem piersiowym rdzenia kręgowego w odcinku piersiowym i lędźwiowo-krzyżowym opóźnione jest siadanie, czworakowanie i chodze- 
nie [2-5]. Rozwój somatyczny jest najbardziej opóźniony $\mathrm{u}$ dzieci z poziomem uszkodzenia rdzenia kręgowego powyżej Th10, a najmniej - z uszkodzeniem poniżej L5 [6]. W stosunku do dzieci zdrowych, dzieci z przepukliną oponowo-rdzeniową są niższe, mają mniejszą masę ciała, słabszy rozwój układu kostnego i mięśniowego oraz nadmiernie rozwiniętą tkankę tłuszczową. U dzieci z przepukliną oponowo-rdzeniową oprócz zaburzenia funkcji zwieraczy, niedowładu lub porażenia dolnych u $81 \%$ dzieci występuje wodogłowie, wymagające leczenia zastawką komorowo-otrzewnową [6-8]. Z powyższym związane są często problemy w rozwoju intelektualnym. Badania rezonansu magnetycznego u dzieci przepukliną oponowo-rdzeniową, oprócz wodogłowia, wykazały zmniejszenie objętości mózgu i móżdżku, nieprawidłowości śródmózgowia mostu, splenium i tectum [9]. Uważa się, że u pacjentów z przepukliną oponowo-rdzeniową za deficyty pamięci, uwagi i ruchów jest odpowiedzialna malformacja mózgu typu Chiari II [10]. Za deficyty uwagi są odpowiedzialne z kolei zmiany w śródmózgowiu, w tylnych obszarach kory mózgu i ciała modzelowatego [11]. Powyższe zmiany mogą wpływać na rozwój umiejętności szkolnych i zachowań adaptacyjnych oraz na poziom inteligencji dzieci.

Badań dotyczących oceny czynników ryzyka wystąpienia nieprawidłowego rozwoju intelektualnego $u$ dzieci z przepukliną oponowo-rdzeniową jest niewiele w Europiei na świecie [12-14], a jeszcze mniej w Polsce. Większość prac dotyczy rozwoju ruchowego pacjentów z przepukliną oponowo-rdzeniową $[6-8,15,16]$. Poznanie czynników wpływających na rozwój intelektualny w tej grupie pacjentów może ułatwić wprowadzenie wcześniejszego programu terapeutycznego stymulującego rozwój funkcji poznawczych.

Celem pracy była ocena czynników mogących mieć wpływ na rozwój intelektualny dzieci i młodzieży z przepukliną oponowo-rdzeniową.

\section{MATERIAŁ I METODY}

Badaniem objęto 52 dzieci i młodzieży z przepukliną oponowo-rdzeniową w wieku 4-17 lat (9,1 $\pm 3,8$ lat), 29 (56\%) dziewcząt oraz 23 (44\%) chłopców będących pod opieką Klinika Rehabilitacji Dziecięcej z Ośrodkiem Wczesnej Pomocy Dzieciom Upośledzonym „Dać Szansę” Uniwersytetu Medycznego w Białymstoku.

Rozwój intelektualny analizowano na podstawie przeprowadzonych wcześniej badań w Poradni Psychologiczno-Pedagogicznej. Stan funkcjonalny pacjentów oceniano za pomocą skali Hoffer'a [16]. Badane dzieci i młodzież podzielono na cztery grupy według skali Hoffer'a: I - pacjenci poruszający się na wózku inwalidzkim, II - poruszający się z dużymi problemami (np: za pomocą kul), III - pacjenci poruszający się z niewielkimi w domu, IV - poruszający się bez ograniczeń. Dodatkowo dokonano analizy zmian w obrębie rdzenia kręgowego: odcinek piersiowo-lędźwiowy, lędźwiowo-krzyżowy, krzyżowy. Wszyscy badani mieli wykonane badania neuroobrazowe głowy (USG, tomografia komputerowa, rezonans magnetyczny).

W analizie czynników mogących mieć wpływ na rozwój intelektualny badanych pacjentów uwzględniono: płeć i wiek pacjentów, czas trwania ciąży, kolejność ciąży, rodzaj porodu (naturalny, cięcie cesarskie, masa urodzeniowa, wynik punktacji skali Apgar, kamienie milowe rozwoju (siadanie, czworakowanie, chodzenie, mowa), poziom uszkodzenia rdzenia kręgowego, obecność wodogłowia, drenaż komoro-otrzewnowy, padaczka oraz wykształcenie rodziców. Wykształcenie wyższe posiadało 9 matek i 8 ojców, średnie 39 matek i 32 ojców, a wykształcenie podstawowe 4 matki i 11 ojców.

W analizie statystycznej, celem oceny zależności pomiędzy rozwojem intelektualnym dzieci i młodzieży z przepukliną oponowo-rdzeniową, a czynnikami mogącymi mieć na nie wpływ, użyto analizę regresji wielorakiej. Za wartości istotne statystycznie przyjęto wartość $p$ $\leq 0,05)$. Do obliczeń użyto programu statystycznego Statistica 13.0 PL (StatSoft, Kraków, Polska).

Na prowadzenie badań uzyskano zgodę Komisji Bioetycznej Uniwersytetu Medycznego w Białymstoku.

\section{WYNIKI}

Liczba chłopców (44\%) i dziewcząt (56\%) objętych badaniem, podobnie miejsce zamieszkania, nie różniła się istotnie. Najliczniejszą grupę $(56 \%)$ stanowiły dzieci i młodzież z przepukliną okolicy lędźwiowo-krzyżowej, mniej liczną grupę pacjenci z lokalizacją piersiowo-lędźwiową (38\%). Lokalizację krzyżową stwierdzono u 6\% badanych.

Rozwój psychoruchowy badanych dzieci był opóźniony w stosunku do ogólnie przyjętych norm dla dzieci zdrowych (np. siadanie było osiągane średnio wieku 11 miesięcy w przypadku dzieci zdrowych jest to najczęściej 7-8 miesiąc). Połowa badanych dzieci poruszała się na wózku inwalidzkim.

$\mathrm{Na}$ podstawie opinii psychologicznej stwierdzono u $27 \%$ rozwój intelektualny poniżej przeciętnej, u 4\% upośledzenie umysłowe w stopniu lekkim, u $8 \%$ upośledzenie umysłowe w stopniu umiarkowanym, a u 4\% upośledzenie umysłowe w znacznym stopniu. Ponad połowa pacjentów (63\%) miało wodogłowie, a padaczkę stwierdzono jedynie w trzech przypadkach (6\%). Szczegółowe dane przedstawia Tabela I.

Dodatnie korelacje stwierdzono pomiędzy rozwojem intelektualnym pacjentów $\mathrm{z}$ przepukliną oponowo-rdzeniową, a wiekiem rozpoczęcia chodzenia (beta $=0,406$; $\mathrm{p}=0,034)$ i wykształceniem matki (beta $=0.497 ; \mathrm{p}=0,010$ ). Wykazano także ujemne zależności pomiędzy rozwojem intelektualnym badanych a stanem funkcjonalnym pacjentów w skali Hoffer'a (beta $=-0,475 ; \mathrm{p}=0,047$ ), obecnością wodogłowia (beta $=-1,158 ; \mathrm{p}=0,05)$ i drenażem komorowo-otrzewnowym (beta $=-1,161 ; \mathrm{p}=0,047$ ) Szczegółowe dane przedstawia Tabela II.

\section{DYSKUSJA}

W obecnym badaniu 39\% dzieci i młodzieży z przepukliną oponowo-rdzeniową miało nieprawidłowy rozwój intelektualny. Wykazano, iż nieprawidłowy rozwój intelektualny badanych pacjentów był zależny od okresu samodzielnego chodzenia, stanu funkcjonalnego, obecności wodogłowia, drenażu komorowo-otrzewnowego oraz wykształcenia 
Tabela I. Dane demograficzne i kliniczne pacjentów z przepukliną oponowo-rdzeniową

Table I. Demographic and clinical data of subjects with meninomyelocele

\begin{tabular}{l}
\hline Wiek/Age \\
Średnia 9,1 1 3,9 lat \\
Zakres 4-17 lat \\
\hline Płeć/Sex \\
Dziewczęta 29 (56\%) \\
Chłopcy 23 (44\%) \\
\hline Miejsce zamieszkania/Place of residence \\
Miasto - 25 (48\%) \\
Wieś - 27 (52\%) \\
\hline Poziom uszkodzenia rdzenia kręgowego/Level of spine injury \\
odcinek piersiowo-lędźwiowy - 20 (38\%) \\
lędźwiowo-krzyżowy - 29 (56\%) \\
krzyżowy - 3 (6\%) \\
\hline Rozwój psychoruchowy/Psychomotor development \\
Siadanie - $11,0 \pm 3,4$ miesięcy \\
Czworakowanie - $13 \pm 9$ miesięcy \\
Chodzenie - $24 \pm 23$ miesięcy \\
Mowa - $15 \pm 5$ miesięcy
\end{tabular}

Stan funkcjonalny w skali Hoffer'a/Functional status in Hoffer's scale

I - pacjenci poruszający się na wózku inwalidzkim $28(54 \%)$

II - poruszający się z dużymi ograniczeniami -7 (13\%)

III - pacjenci poruszający się niewielkimi ograniczeniami - 8 (15\%)

IV - poruszający się bez ograniczeń - 9 (17\%)

Rozwój intelektualny/Mental development
prawidłowy - 32 (61\%)
poniżej przeciętnej $14(27 \%)$
niepełnosprawność intelektualna w stopniu lekkim 2 (4\%)
niepełnosprawność intelektualna w stopniu umiarkowanym
$2(4 \%)$
niepełnosprawność intelektualna w stopniu znacznym 2 (4\%)
Wodogłowie/ Hydrocephalus - 33 (63\%)
Zastawka komorowo-otrzewnowa/Ventriculoperitoneal shunt
32 (61\%)
Padaczka/ Epilepsy - $3(6 \%)$

matki. Nasze wyniki są zgodne z doniesieniami innych autorów [13-15].

W badaniu szwedzkich autorów Lindquist i wsp. [14], stwierdzili nieprawidłowy rozwój intelektualny u 29\% dzieci przepukliną oponowo-rdzeniową. Dzieci z przepukliną oponowo-rdzeniową i wodogłowiem wewnętrznym i drenażem komorowo-otrzewnowym w wieku 8-14 lat miały gorszą pamięć i większe trudności w szkole w porównaniu ze zdrowymi dziećmi. W innym badaniu ze Szwecji przeprowadzonym przez Persson i wsp. [15] wykazali także nieprawidłowy rozwój intelektualny u 47\% dzieci z przepukliną oponowo-rdzeniową i wodogłowiem.

Boyer i wsp. [17] wykazali zaburzenia pamięci i szybkości przetwarzania nowych informacji u dzieci z przepu-

Tabela II. Korelacje pomiędzy rozwojem intelektualnym pacjentów z przepukliną oponowo-rdzeniową a zmiennymi demograficznymi, klinicznymi, rozwoju psychoruchowego oraz wykształceniem rodziców.

Table II. Correlations between mental development of patients with meninomyelocele and demographic, clinical data, psychomotor development and parents' education.

\begin{tabular}{|c|c|c|}
\hline Zmienne/ Variables & $\begin{array}{c}\text { Beta } \\
\text { /Beta coefficient }\end{array}$ & $\begin{array}{c}\text { Wartość } p / \\
P \text { value }\end{array}$ \\
\hline Płeć & $-0,210$ & 0.239 \\
\hline Wiek & $-0,184$ & 0.332 \\
\hline Miejsce zamieszkania & $-0,912$ & 0,060 \\
\hline Skala Hoffera & $-0,475$ & 0,047 \\
\hline Poziom przepukliny & 0,362 & 0,156 \\
\hline Kolejność ciąży & $-0,661$ & 0,110 \\
\hline Poród & 0,543 & 0,175 \\
\hline Tydzień ciąży & $-0,294$ & 0,161 \\
\hline $\begin{array}{l}\text { Punktacja w skali } \\
\text { Apgar }\end{array}$ & $-0,053$ & 0,794 \\
\hline Cięcie cesarskie & $-0,216$ & 0,227 \\
\hline Masa urodzeniowa & 0,170 & 0,429 \\
\hline Siadanie & $-0,040$ & 0,838 \\
\hline Chodzenie & 0,406 & 0,034 \\
\hline Czworakowanie & $-0,339$ & 0,119 \\
\hline Mowa & 0,241 & 0,204 \\
\hline Wodogłowie & $-1,158$ & 0,050 \\
\hline $\begin{array}{l}\text { Drenaż komorowo- } \\
\text {-otrzewnowy }\end{array}$ & $-1,161$ & 0,049 \\
\hline Padaczka & 0,188 & 0,181 \\
\hline Wykształcenie matki & 0,497 & 0,010 \\
\hline Wykształcenie ojca & 0,009 & 0,960 \\
\hline
\end{tabular}

Beta - wpółczynnik regresji wielorakiej; Beta coefficient multiple regression

kliną oponowo-rdzeniową i drenażem komorowo-otrzewnowym w porównaniu z grupą kontrolną. Stwierdzili także, że $60-70 \%$ dzieci po operacjach przepukliny oponowo-rdzeniowej miało prawidłowy rozwój intelektualny. Dane te są zgodne naszymi wynikami, potwierdzającymi prawidłowy rozwój intelektualny u $61 \%$ badanych dzieci.

Rodzaj zastosowanego drenażu może mieć także wpływ na rozwój intelektualny pacjentów $\mathrm{z}$ wodogłowiem. Obecnie metody leczenia wodogłowia można podzielić na cztery grupy: leczenie wodogłowia u płodów, leczenie wodogłowia pokrwotocznego u wcześniaków, leczenie wodogłowia noworodków oraz leczenie wodogłowia endoskopowe. Leczenie endoskopowe wodogłowia jest zabiegiem mniej inwazyjnym, mikrochirurgicznym i powoduje mniej powikłań [18]. Wiśniewska i wsp. [19] porównywali wyniki leczenia operacyjnego dzieci i młodzieży pacjentów z przewlekłym wodogłowiem metodą neuroendoskopową i implantacją zastawki komorowo- 
-otrzewnowej. Przyczynami wodogłowia były najczęściej: wrodzona atrezja wodociagu Sylwiusza, zapalenie opon mózgowo-rdzeniowych oraz krwawienia do komór bocznych mózgu. W grupie pacjentów po implantacji zastawki istotnie statystycznie częściej: występowała padaczka, niepełnosprawność intelektualna oraz zaburzenia lokomocji. Analiza szerokości układu komorowego w zależności od rozwoju intelektualnego i lokomocji ujawniła istotne różnice w grupie pacjentów leczonych na korzyść leczenia endoskopowego. W obecnym badaniu implantacja zastawki komorowo-otrzewnowej była jedyną metodą stosowaną w leczeniu wodogłowia. Nie analizowaliśmy także czasu założenia drenażu komorowo-otrzewnowego.

Padaczka u pacjentów z przepukliną dzieci z przepukliną oponowo-rdzeniową występuje z różną częstością od 5-10\% [20]. Napady padaczkowe oporne na leczenie mogą powodować pogłębienie zaburzeń rozwoju intelektualnego. W naszym badaniu częstość występowania padaczki wyniosła 6\% i nie miała wpływu na częstość występowania niepełnosprawności intelektualnej. Uważa się, że występowanie padaczki u pacjentów z przepukliną oponowo-rdzeniową i wodogłowiem jest zależna od liczby implantacji zastawki i występowania powikłań (zapalenie opon-mózgowordzeniowych, krwawienia, uszkodzenia kory mózgowej) [20].

W patomechanizmie zaburzeń pamięci i niepełnosprawności intelektualnej w przebiegu wodogłowia wyróżnia się ucisk, rozciąganie, i niedotlenienie neuronów z powodu wzrostu objętości i ciśnienia śródczaszkowego. Szczególną rolę przypisuje się hipokampowi, który odgrywa istotną rolę w procesach pamięci. Długotrwały wzrost ciśnienia śródczaszkowego może spowodować zmniejszenie objętości hipokampa oraz pogłębić zaburzenia pamięci [21].

W badaniach neuroobrazowych Vachha i wsp. [9] wykazali zależności pomiędzy nieprawidłowościami w budowie układu limbicznego u dzieci z przepukliną rdzeniową a występowaniem wodogłowia wewnętrznego. Zmiany powyższe wpływały negatywnie na pamięć oraz na naukę dzieci w szkole. Podobnie w obecnym opracowaniu wykazano ujemną korelację pomiędzy występowaniem wodogłowia wewnętrznego a rozwojem intelektualnym badanej grupy.

W literaturze przedmiotu dane na temat występowania wodogłowia u pacjentów przepukliną oponowo-rdzeniową są rozbieżne. Według Elgamal [22] wodogłowie u dzieci z przepukliną oponowo-rdzeniową występuje u 15-25\%. W badaniu z Indii [23] stwierdzono występowanie wodogłowia wewnętrznego u 59\% u dzieci z przepukliną oponowo-rdzeniową w wieku 1,8 - 8 lat. Podobnie w obecnym opracowaniu ponad $60 \%$ pacjentów miało wodogłowie wewnętrzne potwierdzone badaniem tomografii komputerowej lub metodą rezonansu magnetycznego.

Rozwój intelektualny dzieci, także z przepukliną oponowo-rdzeniową związany jest z rozwojem ruchowym. W obecnym badaniu jedynie $17 \%$ poruszało się samodzielnie bez ograniczeń, co jest zgodne z doniesieniami innych autorów. Podobne wyniki uzyskali badacze Bartonek i Saraste, [24], którzy stwierdzili zdolność samodzielnego poruszania się bez ograniczeń u 9 (17\%) spośród 53 dzieci z przepukliną oponowo-rdzeniową, a u 15 (28\%) konieczność poruszania się na wózku inwalidzkim. Nejat [25] z kolei stwierdził, że jedynie $20 \%$ pacjentów z tym schorzeniem poruszało się bez ograniczeń.

Według Fletcher i wsp. [26] poziom uszkodzenia rdzenia kręgowego jest związany także ze zmianami w obrębie ośrodkowego układu nerwowego. W przypadku dzieci i młodzieży, u których poziom uszkodzenia rdzenia dotyczył odcinka piersiowego, w badaniu MRI stwierdzili jakościowe zmiany w obrębie śródmózgowia, tectum, mostu i splenium. Obserwowali także większą redukcję objętości mózgu i móżdżku w porównaniu z pacjentami z poziomem uszkodzenia rdzenia kręgowego w odcinku lędźwiowym. Wykazali również, że opóźnienie rozwoju intelektualnego występowało częściej u osób z lokalizacją przepukliny oponowo-rdzeniowej o odcinku piersiowym.

Ograniczenia obecnego badania wynikają z faktu, że było to badanie retrospektywne, $\mathrm{z}$ dość niewielką badaną grupą. Nie analizowali także czasu założenia zastawki, liczby ponownych implantacji i powikłań po załażeniu zastawki. Ważne jest więc kontynuowanie obecnych badań na większej populacji pacjentów.

\section{PIŚMIENNICTWO}

[1] Zamłyński A., Olejek J., Bohosiewicz J. et al.: Kliniczne aspekty chirurgicznego zamknięcia przepukliny oponowo-rdzeniowej płodu z zespołem Chiari II. PNiG, 2010; 3: 41-47.

[2] Okurowska-Zawada B., Kułak W., Sienkiewicz D., et al.: Analiza czynników epidemiologicznych występowania przepukliny oponowo-rdzeniowej wśród pacjentów Kliniki Rehabilitacji Dziecięcej w Białymstoku. Probl Hig Epidemiol 2011; 92: 298-303.

[3] Perenc L.: Ocena rozwoju somatycznego dzieci operowanych z powodu przepukliny oponowo-rdzeniowej na podstawie analizy częstości występowania pomiarów antropometrycznych w przedziałach wartości przeciętnych i patologicznych. Prz Med Uniw Rzesz Inst Leków 2005; 2: 125-139.

[4] Rocque B.G., Bishop E.R., Scogin M.A., et al.: Assessing health-related quality of life in children with spina bifida. J. Neurosurg Pediatr 2015; 15: 144-149.

[5] Bol K.A., Collins J.S., Kirby R.S.: National Birth Defects Prevention Network. Survival of infants with neural tube defects in the presence of folic acid fortification. Pediatrics, 2006; 117: 803-813.

[6] Oakeshott P, Hunt G.M.: Long-term outcome in open spina bifida. $\mathrm{Br} \mathrm{J}$ Gen Pract 2003; 53: 632-636.

[7] Leslie N., Sutton M.D.: Fetal surgery for neural tube defects. Best Pract Res Clin Obstet Gynaecol 2008; 22: 175-188.

[8] Fletcher J.M., Copeland K., Frederick J.A. et al.: Spinal lesion level in spina bifida: a source of neural and cognitive heterogeneity. J Neurosurg 2005; 102: (3 Suppl), 268- 279.

[9] Vachha B., Adams R.C. Rollins N.K.: Limbic tract anomalies in pediatric myelomeningocele and Chiari II malformation: anatomic correlations with memory and learning-initial investigation. Radiology 2006; 240: 194-202.

[10] Raybaud C., Miller E.: Radiological evaluation of myelomeningocele Chiari II Malformation. In: Ozek M., Cinalli G., Maixner W., editors. Spina Bifida: Management and Outcome. Milan: Springer; 2008. pp. 111-142.

[11] Dennis M., Edelstein K., Frederick J., et al.: Peripersonal spatial attention in children with spina bifida: Associations between horizontal and vertical line bisection and congenital malformations of the corpus callosum, midbrain, and posterior cortex. Neuropsychologia 2005; 43: 2000-2010.

[12] Yeates K.O., Enrile B.G., Loss N., et al.: Verbal learning and memory in children with myelomeningocele. J Pediatr Psychol 1995; 20: 801-815.

[13] Lindquist B., Carlsson G., Persson E.K., et al.: Learning disabilities in a population-based group of children with hydrocephalus. Acta Paediatr 2005; 94: 878-883.

[14] Persson E.K., Hagberg G., Uvebrant P.: Disabilities in children with hydrocephalus-a population-based study of children aged between four and twelve years. Neuropediatrics 2006; 37:3 30-336. 
[15] Hoffer M.M., Feiwell E., Perry R., et al.: Functional ambulation in patients with myelomeningocele. J Bone Joint Surg Am 1973; 55: 137-148.

[16] Okurowska-Zawada B., Sobaniec W., Kutak W., et al.: Analiza rozwoju motorycznego dzieci z przepukliną oponowo-rdzeniową i stosowane metody rehabilitacji. Neurol Dziec 2008; I: 31-38.

[17] Boyer K.M., Yeates K.O., Enrile B.G.: Working memory and information processing speed in children with myelomeningocele and shunted hydrocephalus: analysis of the children's paced auditory serial addition test. J Int Neuropsychol Soc 2006; 12: 305-313.

[18] Polis L.: Wodogłowie u płodu i noworodka. Perinatol Neonatol Ginekol 2009; 2: 218-222.

[19] Wiśniewska B., Mikołajczyk-Wieczorek W, Polis B., et al.: Ocena odległych psychologicznych rezultatów operacyjnego leczenia chorych z wodogłowiem poddanych zabiegom w wieku rozwojowym z wykorzystaniem technik neuroendoskopowych i zastawek Orbis Sigma. Adv Clin Exp Med 2012; 21: 373-384.

[20] Danzer E., Finkel R., Gerdes M., et al.: The relationship of seizure activity and chronic epilepsy in early infancy and short-term neurodevelopmen- tal outcome following fetal myelomeningocele closure. Neuropediatrics 2010; 41: 140-143.

[21] Dombrowski S.M., Deshpande A., Dingwall C., et al.: Chronic hydrocephalus induced hypoxia: increased expression of VEGFR-2, and blood vessel density in hippocampus. Neuroscience 2008; 152: 346-359.

[22] Elgamal E.A.: Natural history of hydrocephalus in children with spinal open neural tube defect. Surg Neurol Int 2012; 3: 112.

[23] Kumar R., Singhal N.: Outcome of meningomyelocele/lipomeningomyelocele in children of northern India. Pediatr Neurosurg 2007; 43: 7-14.

[24] Bartonek A., Saraste H.: Factors influencing ambulation in myelomeningocele: a cross-sectional study. Dev Med Child Neurol 2001; 43: 253-260.

[25] Nejat F., Kazmi S.S., Habibi Z., et al.: Intelligence quotient in children with meningomyeloceles: a case-control study. J Neurosurg 2007; $106(2$ Suppl): 106-110.

[26] Fletcher J.M., Copeland K., Frederick J.A., et al.: Spinal lesion level in spina bifida: a source of neural and cognitive heterogeneity. J Neurosurg 2005; 102(3 Suppl): 268-279. 
